\title{
OUTCOME OF SURFACTANT REPLACEMENT THERAPY IN PRETERM BABIES WITH HYALINE MEMBRANE DISEASE AT NEONATAL INTENSIVE CARE UNIT OF A TERTIARY HOSPITAL
}

\author{
Manandhar $S R^{1^{*}}$
}

\section{Affiliation}

1. Associate Professor and Head, Neonatal unit, Department of Pediatrics, Kathmandu Medical College Teaching Hospital, Sinamangal

\section{ARTICLE INFO}

\section{Article History}

$$
\begin{array}{ll}
\text { Received } \quad \text { : } & 11 \text { August, } 2018 \\
\text { Accepted } & : \text { 26 October, } 2018 \\
\text { Published } & : \quad 31 \text { December, } 2018
\end{array}
$$

(C) Authors retain copyright and grant the journal right of first publication with the work simultaneously licensed under Creative Commons Attribution License CC - BY 4.0 that allows others to share the work with an acknowledgment of the work's authorship and initial publication in this journal.

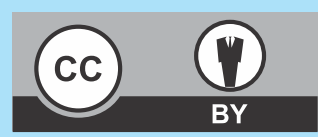

ORA 86

DOI: $\underline{10.3126 / \text { bjhs.v3i3.22171 }}$

\author{
* Corresponding Author \\ Dr Sunil Raja Manandhar \\ Associate Professor and Head, Neonatal Unit \\ Department of Pediatrics \\ Kathmandu Medical College Teaching Hospital, Sinamangal \\ Email: drsunilraja@gmail.com \\ ORCID ID: https://orcid.org/0000-0002-6583-3973
}

\section{Citation}

Manandhar SR. Outcome of Surfactant Replacement Therapy in Preterm Babies with Hyaline Membrane Disease at Neonatal Intensive Care Unit of A Tertiary Hospital. BJHS 2018;3(3)7: 537-541.

\section{ABSTRACT}

\section{Introduction}

Hyaline membrane disease (HMD) is an acute lung disease of preterm babies caused by surfactant insufficiency. Decreased surfactant results in insufficient surface tension in the alveolus during expiration leading to alveolar collapse, atelectasis, impaired gas exchange, severe hypoxia and acidosis, leading to respiratory failure. Surfactant replacement therapy (SRT) is now accepted as the standard treatment of preterm babies with HMD.

\section{Objective}

The objective of this study was to analyze the outcome of surfactant replacement therapy in preterm babies with hyaline membrane disease.

\section{Methodology}

This is a prospective observational study conducted at 10 bedded neonatal unit of Pediatrics Department, Kathmandu Medical College Teaching Hospital, Sinamangal. Study duration was of one year period $\left(15^{\text {th }}\right.$ May $2017-14^{\text {th }}$ May 2018). Preterm babies from 26 wks -35 wks of gestation with Hyaline Membrane Disease were included in this study whereas babies with lethal congenital malformations eg: Meningomyelocele, Anencephaly, Gastrochisis, Diaphragmatic Hernia were excluded. All preterm babies who had clinical and radiological features of HMD were considered for Surfactant Replacement Therapy (SRT).

The surfactant (Survanta; Abbott Laboratories, USA; Dose: 4 $\mathrm{ml} / \mathrm{kg}$ ) was administered intra-tracheally according to standard procedures in four divided aliquot applying INSURE (intubation, surfactant administration and extubation to Bubble CPAP) Technique. Ethical clearance was received from Institutional Review Committee (IRC) of Kathmandu Medical College and Statistical analysis was done with SPSS 19 version with frequency and cross tabulation.

\section{Results}

In this study of 30 preterm babies with HMD received SRT, $47 \%$ (14) were male and $53 \%(16)$ were female. The mean birth weight of preterm babies with HMD was $1372.17 \pm 395$ gms and mean gestational age was $30.1 \pm 2.6$ weeks. Among 30 preterm babies with HMD receiving SRT, 73.3\% (22 babies) discharged from the hospital and 6.3\% (8 babies) expired. Among eight expired babies, five died due to pulmonary hemorrhage and three died due to septicemia with DIC. Maximum survival was seen in the gestational age of 30-35 wks and birth weight 1200-2100gms.

\section{Conclusion}

The use of SRT has improved the survival outcome and decreased the associated morbidities in babies with HMD. The maximum impact of survival was seen among the preterm babies of 3035 weeks with birth weight of $1200-2100$ grams.

\section{KEYWORDS}

Hyaline Membrane Disease, Preterm babies, Surfactant Replacement Therapy. 


\section{INTRODUCTION}

In developing countries, neonatal deaths account for more than one third of all deaths in children under the age of five. ${ }^{1}$ Mortality rates are very high in the early neonatal period with $25 \%-45 \%$ occurring in the first 24 hours of life, and about $2 / 3^{\text {rd }}$ of them occurring during the first week of life. ${ }^{2}$ Respiratory Distress Syndrome (RDS) or Hyaline Membrane Disease (HMD), has been recognized as the most common complication of prematurity, with more than half of those occurring between birth weight 501-1500 gms showing signs of RDS. ${ }^{3,4}$

Hyaline Membrane Disease (HMD) of the newborn is an acute lung disease of premature babies caused by insufficient surfactant production in alveolus. Insufficient surfactant results in increased surface tension in the alveolus during expiration leading to alveolar collapse, atelectasis, decreased gas exchange, severe hypoxia with acidosis, leading to respiratory failure. In preterm babies with HMD, exogenous surfactant helps to reduce pulmonary air leaks by $50 \%$ and neonatal mortality by $30 \%{ }^{5}$ Administration of natural surfactant reduces acute respiratory disease, air leaks, bronchopulmonary dysplasia, and mortality in preterm infants. ${ }^{6}$ Surfactant replacement therapy (SRT) is now accepted as the standard treatment protocol for preterm babies with HMD. 'SRT is also helpful for babies with hypoxic respiratory failure, secondary surfactant deficiency in meconium aspiration syndrome, sepsis, pneumonia, and pulmonary hemorrhage. ${ }^{8}$ So, the main objective of this study was to analyze the outcome of surfactant replacement therapy in preterm babies with HMD.

\section{METHODOLOGY}

This is a prospective observational study done at 10 bedded; level III Neonatal Intensive Care Unit (NICU) of Pediatrics Department, Kathmandu Medical College Teaching Hospital. Perinatal Mortality Rate (PMR) of this tertiary hospital is $10 / 1000$ births and Neonatal mortality rate (NMR) is $4.5 / 1000$ live births. Total delivery at this hospital is around 4000 per year. The study duration was of one year period $\left(15^{\text {th }}\right.$ May $2017-14^{\text {th }}$ May 2018). Preterm babies' with gestational age from $26-35$ wks and birth weight 715-2100 gms with HMD were included in this study whereas preterm babies with lethal congenital anomalies (eg. Meningomyelocel, Anencephaly, Gastrochisis, Diaphragmatic Hernia) were excluded. All preterm babies who had clinical and radiological features of HMD were considered for SRT. For the assessment of respiratory distress in preterm babies, Silverman's Scoring was done at 1 hour of life in all 30 babies. ${ }^{9}$

Under aseptic precautions, the surfactant (Survanta; Abbott Laboratories, USA; Dose: $4 \mathrm{ml} / \mathrm{kg}$ ) was administered intratracheally according to standard procedures in four divided aliquot applying INSURE \{intubation, surfactant administration and extubation to Bubble Continuous Positive Airway Pressure (CPAP) \} technique. ${ }^{10}$ After introduction of surfactant, intermittent inflation breath was given via Ambu
Bag. Heart rate, SPO2 and ECG monitoring was done throughout the procedure. Intra tracheally surfactant was given as rescue therapy within 12 hours of birth once specified threshold criteria for diagnosis of HMD was fulfilled. Second dose of Surfactant therapy was considered 12 hours after the first dose, in babies who still need Bubble CPAP (continuous positive airway pressure) or Mechanical Ventilator with $\mathrm{FiO}_{2}>50 \%$ and baby is still tachynoic after first dose of SRT. For the diagnosis of HMD in preterm babies following both criteria were used:

1. HMD is an acute lung disease of preterm babies with the classic clinical presentation characterized by a respiratory rate $>60 / \mathrm{min}$, dyspnoea (intercostals, subcostal in drawing, sternal retraction, nasal flaring, cyanosis) with a predominantly diaphragmatic breathing and a characteristic expiratory grunting within $4-6 \mathrm{~h}$ of delivery. ${ }^{11}$

2. A chest radiograph consistent with HMD (reticulogranular appearance to lung fields with or without low lung volumes and air bronchograms) within the first $24 \mathrm{hr}$ of life. For practical purposes, the classification of HMD from grade I to III (I - light HMD; II - moderate HMD; IIIsevere HMD) were done according to the chest $x$-ray appearance ranging from a light reticulogranular pattern with air bronchograms to whiteout lungs, adapted from the classification of Couchard et al. ${ }^{12}$

Ethical clearance was received from Institutional Review Committee (IRC) of Kathmandu Medical College and written/ verbal informed consent was taken from parents after explaining the benefits and possible complications of surfactant replacement therapy. Statistical analysis was done with SPSS 19 version with frequency and cross tabulation.

\section{RESULTS}

In total, 30 preterm babies with HMD who received SRT were included in this study. Among them, 47\% (14) were male and $53 \%$ (16) were female. Demographics and clinical characteristics of the study population $(n=30)$ are reported in Table 1. The mean birth weight of preterm babies with HMD receiving SRT was $1372.17 \pm 395$ gms and mean gestational age was $30.1 \pm 2.6$ weeks. Similarly, mean Silverman's scoring for assessment of respiratory distress at 1 hour of life was $6.07 \pm 1.28$ and chest retraction, tachypnea with grunting started at $1.83 \pm 1.14 \mathrm{hr}$ of life. In radiologically $60 \%$ (18) of babies were diagnosed as grade III HMD in Chest $X$-ray. Mean age of $1^{\text {st }}$ dose of SRT for 30 babies were done at $10.17 \pm 6.9$ hrs of life whereas 8 babies required $2^{\text {nd }}$ dose of SRT at $29.62 \pm 12.2 \mathrm{hrs}$ of life. After SRT, the mean duration of preterm babies with HMD kept under Bubble CPAP was $52.40 \pm 30.7 \mathrm{hrs}$ whereas mean duration of preterm babies under mechanical ventilation was $6 \pm 12.7 \mathrm{hrs}$.

Table 2 illustrates only $17.7 \%$ (5) mothers received two doses of Dexona $12 \mathrm{hrs}$ apart before the delivery of preterm babies. $77.6 \%$ (23) preterm babies did not require any form of resuscitation at birth. While analyzing the outcome of SRT among 30 preterm babies, $73.3 \%(22)$ of babies were 
discharged whereas $6.3 \%(8)$ babies expired. The mean hospital stay of 22 survived babies was $14.95 \pm 6.25$ days (Table 1). Among survived 22 babies, only 1 baby developed Retina of Prematurity (ROP) whereas five preterm babies died due to Pulmonary Hemorrhage and three babies died due to sepsis with DIC (Disseminated intravascular coagulation) shown in Table 2.

On cross tabulation analysis, Table 3 explains co-relation of birth weight in respect to baby's outcome. Maximum survival was seen among babies with the birth weight of $1200 \mathrm{gms}$ and more. Out of 22 survived babies, 15 were with birth weight $1200-2100$ gms. Similarly, Table 4 explains co-relation of gestational age with respect to baby's outcome. Out of 22 survived babies, 13 preterm babies were of 30-35 wks of gestational age. The result showed maximum survival of babies were found in-between the gestational age 30-35 wks and birth weight 1200-2100gms respectively.

\begin{tabular}{|c|c|c|c|}
\hline S.N. & Variables & Mean & Range \\
\hline 1 & Gestational Age & $30.1 \pm 2.6 \mathrm{wks}$ & $(26-35)$ wks \\
\hline 2 & Birth weight & $1372.17 \pm 395 \mathrm{gms}$ & (715-2100)gms \\
\hline 3 & Silverman's score at $1 \mathrm{hr}$ of birth & $6.07 \pm 1.2$ & $(5-8)$ \\
\hline 4 & $\begin{array}{l}\text { Grunting, Tachypnea, chest Retraction started } \\
\text { after birth }\end{array}$ & $1.83 \pm 1.14 \mathrm{hrs}$ & (1-4) hrs \\
\hline 5 & Apgar Score at $1 \mathrm{~min}$ & $6.03 \pm 1.15$ & $(2-7)$ \\
\hline 6. & Apgar Score at $5 \mathrm{~min}$ & $7.53 \pm 0.77$ & $(5-9)$ \\
\hline 7 & Mothers Age & $28.03 \pm 4.1$ yrs & $(19-39)$ yrs \\
\hline 8 & Duration of Bubble CPAP (with Fio2 Blender) & $52.40 \pm 30.7 \mathrm{hrs}$ & $(10-130) \mathrm{hrs}$ \\
\hline 9 & Duration of Mechanical Ventilation & $6 \pm 12.7 \mathrm{hrs}$ & $(0-50) \mathrm{hrs}$ \\
\hline 10 & Radiologically Lung expansion duration & $34.93 \pm 21.4 \mathrm{hrs}$ & $(12-80) \mathrm{hrs}$ \\
\hline 11 & $1^{\text {st }}$ dose surfactant application ( 30 babies) & $10.17 \pm 6.9 \mathrm{hrs}$ & $(2-28) \mathrm{hrs}$ \\
\hline 12 & $2^{\text {nd }}$ dose surfactant application ( 8 babies) & $29.62 \pm 12.2 \mathrm{hrs}$ & $(18-54) \mathrm{hrs}$ \\
\hline 13 & Hospital Stay ( 22 babies) & $14.95 \pm 6.25$ days & (8- 32 )days \\
\hline
\end{tabular}

\begin{tabular}{|c|c|c|c|}
\hline S.N. & Variables & No & (\%) \\
\hline \multirow[t]{4}{*}{1} & $\begin{array}{l}\text { Antenatal } 2 \text { doses of Dexona } \\
12 \text { hrs apart }\end{array}$ & & \\
\hline & Yes & 5 & (17.7) \\
\hline & No & 25 & $(83.3)$ \\
\hline & Total & 30 & $(100)$ \\
\hline \multirow[t]{5}{*}{2} & $\begin{array}{l}\text { Resuscitation procedure done } \\
\text { at birth }\end{array}$ & & \\
\hline & Not required & 23 & (77.6) \\
\hline & Bag n Mask & 6 & (20.1) \\
\hline & Tactile stimulation & 1 & (3.3) \\
\hline & Total & 30 & $(100)$ \\
\hline \multirow[t]{4}{*}{3.} & $\begin{array}{l}\text { Outcome of preterm babies } \\
\text { with HMD }\end{array}$ & & \\
\hline & Discharged & 22 & $(73.3)$ \\
\hline & Expired & 8 & $(6.3)$ \\
\hline & Total & 30 & $(100)$ \\
\hline \multirow[t]{4}{*}{5.} & $\begin{array}{l}\text { Morbid condition of survived } \\
\text { preterm babies }\end{array}$ & & \\
\hline & Normal & 21 & $(95.4)$ \\
\hline & Retina of Prematurity (ROP) & 1 & $(4.6)$ \\
\hline & Total & 22 & $(100)$ \\
\hline \multirow[t]{4}{*}{6.} & Cause of death & & \\
\hline & Pulmonary hemorrhage & 5 & $(62.5)$ \\
\hline & Sepsis with DIC & 3 & (37.5) \\
\hline & Total & 8 & (100) \\
\hline
\end{tabular}

Table 3: Cross tabulation on birth weight with respect to outcome of babies $(n=30)$

\begin{tabular}{|c|c|c|c|c|}
\hline & \multicolumn{3}{|c|}{ Outcome of babies } & \multirow[b]{2}{*}{$p$ value } \\
\hline Birth weight (gms) & Discharged & Expired & Total & \\
\hline 715 & 1 & 0 & 1 & \multirow{22}{*}{0.37} \\
\hline 780 & 0 & 1 & 1 & \\
\hline 950 & 0 & 1 & 1 & \\
\hline 1000 & 1 & 2 & 3 & \\
\hline 1020 & 2 & 0 & 2 & \\
\hline 1030 & 1 & 0 & 1 & \\
\hline 1080 & 1 & 0 & 1 & \\
\hline 1100 & 1 & 0 & 1 & \\
\hline 1200 & 4 & 0 & 4 & \\
\hline 1400 & 1 & 0 & 1 & \\
\hline 1420 & 1 & 0 & 1 & \\
\hline 1450 & 1 & 0 & 1 & \\
\hline 1500 & 1 & 0 & 1 & \\
\hline 1520 & 1 & 0 & 1 & \\
\hline 1600 & 1 & 1 & 2 & \\
\hline 1700 & 1 & 0 & 1 & \\
\hline 1780 & 1 & 0 & 1 & \\
\hline 1800 & 1 & 1 & 2 & \\
\hline 1900 & 1 & 0 & 1 & \\
\hline 2000 & 1 & 0 & 1 & \\
\hline 2100 & 0 & 2 & 2 & \\
\hline Total & 22 & 8 & 30 & \\
\hline
\end{tabular}




\begin{tabular}{|c|c|c|c|c|}
\hline \multirow[b]{2}{*}{$\begin{array}{l}\text { Gestational } \\
\text { age (wks) }\end{array}$} & \multicolumn{3}{|c|}{ Outcome of babies } & \multirow[b]{2}{*}{$p$ value } \\
\hline & Discharged & Expired & Total & \\
\hline 26 & 1 & 1 & 2 & \multirow{11}{*}{0.53} \\
\hline 27 & 2 & 0 & 2 & \\
\hline 28 & 4 & 1 & 5 & \\
\hline 29 & 2 & 2 & 4 & \\
\hline 30 & 6 & 2 & 8 & \\
\hline 31 & 0 & 1 & 1 & \\
\hline 32 & 2 & 0 & 2 & \\
\hline 33 & 1 & 0 & 1 & \\
\hline 34 & 1 & 1 & 2 & \\
\hline 35 & 3 & 0 & 3 & \\
\hline Total & 22 & 8 & 30 & \\
\hline
\end{tabular}

\section{DISCUSSION}

$\mathrm{HMD}$ is an acute illness in preterm babies due to surfactant insufficiency in lung alveoli. HMD is a major cause of morbidity and mortality in preterm babies. EuroNeoStat Annual Report for Very Low Gestational Age Infants 2010 showed a prevalence of $92 \%$ for HMD in newborn babies with a gestational age of $24-25$ weeks, $88 \%$ at $26-27$ weeks, $76 \%$ at $28-29$ weeks and $57 \%$ at $30-31$ weeks suggesting $\mathrm{HMD}$ incidence is inversely proportional to gestational age i.e less gestational age, more chance of HMD. ${ }^{13}$ Surfactant is necessary for inflation of lung alveoli by reducing its surface tension. Clinical trials have confirmed that surfactant replacement therapy is effective in improving the immediate need for respiratory support and the clinical outcome of premature newborns.

Femitha $\mathrm{P}$ et al in Jawaharlal Institute of Postgraduate Medical Education \& Research (JIPMER), Pondicherry, India, did a study on 101 preterm babies ( 28 wks - 34 wks) who received SRT as rescue therapy in HMD. The survival rate of preterm babies with SRT was 73.3\% (62 babies) and found sepsis (43.5\%), apnea (4.9\%) and pulmonary hemorrhage (3.9\%) as a co-morbid condition. It was very apathetic that only $20.8 \%$ mother received complete course of antenatal steroids. ${ }^{14}$ Similarly, in this study (at Kathmandu Medical College Teaching Hospital), survival rate after SRT in preterm babies with HMD was $73.3 \%$ (22 out of 30 preterm babies) and common co-morbid condition observed were pulmonary hemorrhage $(62.5 \%)$ and Sepsis with DIC (37.5\%). It was also so apathetic that only $17.7 \%$ (5) mothers received complete course ( 2 doses 24 hours apart) of
Dexona before the delivery of their baby.

In another study by Narang A et al in Postgraduate Institute of Medical Education \& Research (PGIMER), Chandigarh, India, received 88 preterm babies with surfactant replacement therapy. The mean gestational age was $30.7 \pm 2$ wks and mean birth weight was $1387 \pm 46$ gms with survival rate was $75 \%$ and mean hospital stay was $14.5 \pm 12.1$ days. ${ }^{15}$ In this study at Kathmandu Medical College Teaching Hospital, mean birth weight of babies receiving SRT was $1372.17 \pm 395$ gms, mean gestational age $30.1 \pm 2.6$ weeks and mean hospital stay $14.95 \pm 6.25$ days suggestive of comparable outcomes in both studies. Survival outcome in this study showed birth weight $\geq 1200$ gms and gestation $\geq$ 30 wks, which was quite similar to the Narang A et al study (Gestational age $\geq 30$ wks and birth weight $\geq 1000 \mathrm{gms}$ ).

A multi centre study in Newyork by Kendig JW et al has shown "rescue" surfactant replacement therapy is equally efficacious and comparable as early 'prophylactic' surfactant replacement therapy for preterm babies with $\mathrm{HMD} .{ }^{16}$ So, in developing countries like Nepal, due to lack of affordability, "rescue" surfactant replacement therapy is usually practiced and in this study at Kathmandu Medical College Teaching Hospital also "rescue" surfactant replacement therapy among 30 preterm babies with HMD was practiced. .

\section{CONCLUSION}

Probably this is the first study done in Nepal highlighting the positive impact of SRT in preterm babies with HMD. The use of SRT has improved the survival outcome and decreased the associated morbidities in babies with HMD. The maximum impact of survival was seen among the preterm babies of 30-35 weeks gestation and birth weight group of $1200-2100$ grams. This study has also shown that SRT followed by Bubble CPAP has significantly reduced the subsequent need for mechanical ventilation.

\section{ACKNOWLEDGEMENT}

My sincere hearty thanks and acknowledgment to all the Pediatric faculties and post graduate residents for their tireless effort and contribution in NICU to make this study successful.

\section{CONFLICT OF INTEREST}

I declare no conflict of Interest

\section{REFERENCES}

1. Lawn JE, Cousens S, Zupan J, for the Lancet Neonatal Survival Steering Team. 4 million neonatal deaths: When? Where? Why? The Lancet 2005;365:891-900. DOI: 10.1016/S01406736(05)71048-5.

2. Zupan J, Aahman E. Perinatal mortality for the year 2000: estimates developed by WHO. Geneva: World Health Organization, 2005.

3. Hack M, Fanaroff AA. Outcomes of extremely-low-birth-weight infants between 1982 and 1988. N Engl J Med 1989;321:1642-47. DOI: 10.1056/NEMJ199005033221814

4. Hack M, Horbar JD, Malloy MH, Tyson JE, Wright E, W right L. Very low birth weight outcomes of the National Institute of Child Health and Human Development Neonatal Network. Pediatrics 1991; 87:587-97. DOI: 10.1016/0002-9378(95)90628-2.

5. Robertson PA, Sniderman SH, Laros RK, Cowan R, Heilbron D, Goldenberg RL et al. Neonatal morbidity according to gestational age and birth weight from five tertiary care centers in the United States, 1983 through 1986. Am J Obstet Gynecol 1992; 166: 162941. DOI: 10.1016/0002-9378(92)91551-k. 
6. Seger N, Soll R. Animal derived surfactant extract for treatment of respiratory distress syndrome. Cochrane Database of Systematic Reviews 2009, Issue 2. Art. No.: CD007836; DOI: 10.1002/ 14651858.CD007836.

7. Agrawal R, Paul VK, Deorari AK. Newborn Infants. In: Paul VK, Bagga A editors. Ghai Essential of Pediatrics. 8thedition.New Delhi: CBS publisher and distributor; 2013: $p-169$.

8. Polin RA, Waldemar CA and Committee on fetus and newborn. Surfactant replacement therapy for preterm and term neonates with respiratory distress. PEDIATRICS Jan 2014; 133 (1): 159. DOI :10.1542/peds.2013-3443IAT

9. Askin DF. (2002). Complications in the transition from fetal to neonatal life. Journal of Obstetric, Gynecologic \& Neonatal Nursing.31 (3):318.DOI: 10.1111/j.1552-6909.2002.tb00054

10. Soll RF. Synthetic surfactant for respiratory distress syndrome in preterm infants (Cochrane Review). In: The Cochrane Library, Issue 4, 2004. Chichester: John Wiley \& Sons, Ltd.

11. Greenough A, Roberton NRC. Acute respiratory disease in the newborn. In: Rennie JM, Roberton NRC, editors. Textbook of neonatology. 3rd ed. Edinburgh: Churchill Livingstone; 2000.pp 481-607.
12. Couchard M, Polge J, Bomsel F. Hyaline membrane disease; diagnosis, radiological surveillance, treatment and complications. Ann Radiol 1974; 669-683. PMID: 4460832.

13. EuroNeoStat. Annual Report for Very Low Gestational Age Infants 2010. Barakaldo, Spain: The ENS Project.

14. Femitha P, Rojo Joy, Adhisivam B, Prasad K, Bahubali DG, Bhat VB. Surfactant Replacement Therapy (SRT) in Respiratory distress syndrome (RDS). Curr Pediatr Res 2012; 16 (2): 134-136.

15. Narang A, Kumar P, Dutta S, Kumar R. Surfactant therapy for hyaline membrane Disease: The Chandigarh experience. Indian Pediatrics 2001; 38: 640-646. PMID: 11418729

16. Kendig JW, Notter RH, Cox C, Reubens LJ, Davis JM, Maniscalco WM et al. A comparison of surfactant as immediate prophylaxis and as rescue therapy in newborns of less than 30 weeks gestation. N Engl J Med 1991, 324: 865-887. DOI: 10.1056/NEJM199103283241301 